\title{
BREVES OBSERVAÇÕES SOBRE OS PRINCÍPIOS DA IMPARCIALIDADE E NEUTRALIDADE DO MEDIADOR: CONCEITUAÇÃO, IMPORTÂNCIA E ALCANCE PRÁTICO DESSES PRINCÍPIOS EM UM PROCESSO DE MEDIAÇÃO / BRIEF NOTES ON THE PRINCIPLES OF THE IMPARTIALITY AND NEUTRALITY OF MEDIATOR: CONCEPT, IMPORTANCE AND PRACTICAL RANGE OF THESE PRINCIPLES IN A MEDIATION
}

\author{
Vitor Carvalho Lopes ${ }^{1}$
}

\begin{abstract}
Resumo
O presente artigo visa estabelecer as distinções entre os princípios da imparcialidade e da neutralidade no âmbito da mediação.

Desse modo, a correta compreensão e análise do enquadramento dos contornos básicos desses princípios, bem como a análise adequada de suas decorrências práticas somente contribuirão para uma maior operosidade desse novo mecanismo de solução de disputas.
\end{abstract}

Palavras-chave: Princípio da imparcialidade. Princípio da neutralidade. Mediação. Mecanismos de solução alternativa de disputas.

\begin{abstract}
This article aims to draw the distinctions between the principles of impartiality and neutrality in the context of mediation.

Thus, the proper understanding and analysis of the basic contours of the framework of these principles, as well as the proper analysis of their practices derivations only contribute to greater solicitude this new mechanism for resolving disputes.
\end{abstract}

Keywords: Principle of impartiality. Principle of neutrality. Mediation. Mechanisms of alternative dispute resolution.

1. Apresentação do trabalho

\footnotetext{
${ }^{1}$ Mestre em Direito Processual da Universidade do Estado do Rio de Janeiro. Participante do Curso de Pós Graduação em Mediação Familiar da Universidade de Burgos - Espanha. Membro Efetivo da Comissão de Mediação de Conflitos da OAB-RJ. Advogado no Rio de Janeiro e em São Paulo.
} 
O presente trabalho visa a expor de maneira breve algumas reflexões sobre dois princípios que sem sombra de dúvida constituem matéria de suma importância para um correto enquadramento da atividade do mediador e que, não raras às vezes são tratados de maneira indistinta pela doutrina, como se estivessem a tratar do mesmo fenômeno.

Assim é que os princípios da imparcialidade e neutralidade do mediador serão aqui tratados como verdadeiros vetores a guiarem a conduta do mediador dentro da dinâmica de um processo de mediação, ressaltando, nesse ínterim, a importância de sua efetiva observação para uma maior operosidade desse mecanismo complementar de solução de disputas $^{2}$, ainda de pouca utilização e conhecimento da comunidade jurídica nacional.

Nessa empreitada, será analisado em um primeiro momento o princípio da imparcialidade, as suas linhas gerais, os seus contornos básicos, enfim, o seu núcleo essencial, inclusive à luz da legislação estrangeira e do projeto de lei de mediação em curso no Congresso Nacional.

Em seguida, será demonstrada a importância de sua efetiva observação pelo mediador dentro de um processo de mediação em seus mais variados aspectos, bem como o alcance prático desse princípio em suas mais variadas projeções, inclusive, naquelas hipóteses que, dada a sua importância, o legislador houve por bem em elevá-las ao grau de normas jurídicas (ao menos em estado potencial, dado não existir até o presente momento uma lei em sentido formal sobre esse instituto).

\footnotetext{
${ }^{2}$ Adota-se essa nomenclatura em razão de repudiarmos as seguintes nomenclaturas que, em nosso entender, contêm termos ou que se encontram equivocados ou que não abarcam todo o núcleo comum dos mecanismos de solução de disputas. São elas: "Equivalentes Jurisdicionais", "Métodos não Adversariais de Solução de Conflitos", "Mecanismos Extrajudiciais de Solução de Conflitos", "Mecanismos Alternativos de Solução de Conflitos". Resumidamente pode-se dizer que a primeira expressão pode sugerir a falsa idéia de que atos produzidos nesses mecanismos de composição de conflitos seriam jurisdicionais, o que, como se sabe é um equívoco. Além disso, poderia supor que tais métodos pudessem substituir a jurisdição, o que definitivamente não é verdade. Quanto à segunda nomenclatura, verifica-se que não se concebe como possa a arbitragem, por exemplo, ser considerada como um mecanismo não adversarial de conflito, o que também nos leva a afastá-la, até mesmo porque não a reputamos a mais conveniente. No que se refere à terceira designação, maiores esclarecimentos são mesmo até desnecessários, eis que o termo extrajudicial é por demais restrito para abarcar o núcleo comum de todos os mecanismos de solução de conflitos, bastando, para tanto, lembrar que determinadas espécies de mecanismos de solução de conflitos podem ocorrer na via judicial (ex: conciliação, termo de ajustamento de conduta, dentre outros). Por fim, quanto à última nomenclatura, verifica-se que o termo alternativo não designa adequadamente esse fenômeno, na medida em que muitos deles, por serem mecanismos autocompositivos são - ou ao menos deveriam ser - a primeira opção para a solução de conflitos. O caráter substitutivo e secundário da Jurisdição vem a afirmar o que se está a aqui expor. Para maiores informações, vide o nosso trabalho ainda não publicado. LOPES, Vitor Carvalho. "A Mediação como importante instrumento de efetivação do princípio do acesso à justiça: limites e possibilidades no sistema jurídico brasileiro". 2008. 197f. Dissertação de Mestrado - Universidade do Estado do Rio de Janeiro (UERJ), Rio de Janeiro, 2008.
} 
Após isso, será examinado o princípio da neutralidade, mediante um confronto analítico ao conceito da imparcialidade, demonstrando, com isso, os diferentes espaços de conformação que tais postulados possuem dentro da dogmática jurídica.

Em seguida, será demonstrada a importância da observância desse princípio pelo mediador no exercício de sua função, o tratamento que lhe é conferido pelas legislações dos mais variados países que adotam a mediação, bem como pelo projeto de lei de mediação em curso no Congresso Nacional, passando finalmente para a análise das situações práticas decorrentes da incidência princípio, incluindo aí, as dificuldades inerentes de se levar ao extremo, a aplicação da idéia de neutralidade em um processo dessa natureza.

Por fim, encerra-se esse estudo com a elaboração de uma pequena síntese conclusiva sobre o presente tema, trazendo nesse bojo as nossas principais reflexões a seu respeito.

2. Princípio da Imparcialidade

\subsection{Conceituação e importância}

Em breves palavras, entende-se que o princípio da imparcialidade vem a designar a proibição de qualquer conduta por parte do mediador que importe em qualquer favorecimento de tratamento a uma das partes. Veja-se, portanto, que a imparcialidade quer se referir à atitude do mediador em relação às partes e não ao conteúdo em si do tema afeto à mediação, questão essa que se abordará mais adiante quando se tratar da neutralidade do mediador.

Tal é a importância desse princípio para a compreensão do instituto em foco, que se atreve a se aqui afirmar que, na realidade, ele é um elemento intrínseco a seu conceito, dele fazendo inarredavelmente parte.

Com isso, o que se quer dizer é que, qualquer norma legal que vise a regulamentar a mediação em seus mais variados aspectos não poderá dela se afastar, sob pena de restar completamente desnaturado esse mecanismo complementar de solução de disputas.

Assim, não é possível se conceber a regularidade de um processo de mediação, na qual, não reste invariavelmente observado este princípio.

Isso significa dizer que onde não há imparcialidade do mediador, não existe um processo de mediação válido, sendo essa uma regra de ouro que se deve observar a todo custo dentro de um processo de mediação.

Prova disso, aliás, é que todas as conceituações legais em torno da mediação vêm a ratificar o que se está aqui expondo, bastando, notar, a título de mera exemplificação, que as 
leis de mediação familiar de Castilla y León e Valenciana, bem como o preâmbulo do documento elaborado pela American Arbitration Association, American Bar Association e Association For Conflict Resolution denominado "Model Standards of Conduct for Mediators" levam em conta a sua presença ${ }^{34}$, de maneira que não é possível se conceber a existência desse mecanismo de solução de disputas, sem a observância desse princípio.

No âmbito doutrinário, a situação não é diferente. Assim é que ROBERTO A. BIANCHI $^{5}$ define a mediação como um procedimento informal, voluntário e sob condição de confidencialidade, conduzido por um terceiro imparcial e aceito pelas partes em disputa, que facilita o diálogo entre as mesmas, possibilitando que elas cheguem a um acordo elaborado por elas próprias (tradução nossa).

Nessa mesma direção, JOSÉ MARIA ROSSANI GARCEZ ${ }^{6}$ ensina que a mediação, enquanto fórmula de solução de conflitos, surge quando "um terceiro imparcial auxilia as

partes a chegarem, elas próprias, a um acordo entre si, através de um processo estruturado.”

De todo modo, o que é importante se ter em mente nesse momento é que o projeto de lei de mediação hoje em curso no Congresso Nacional parece referendar a linha de entendimento aqui exposta, ao estabelecer em seu artigo $2^{\circ}$ que "para os fins desta Lei, mediação é a atividade técnica exercida por terceiro imparcial que, escolhido ou aceito, pelas partes interessadas, as escuta, orienta e estimula, sem apresentar soluções (...)".

\subsection{Alcance prático}

Uma vez expostas as linhas gerais do princípio da imparcialidade, cabe destacar algumas questões que emanam desse postulado, já que é evidente a sua incidência na configuração dos lineamentos básicos da mediação.

O primeiro ponto que se aborda, por força da observância desse princípio, é aquele referente ao fato do mediador ter que evitar a tomar uma atitude que possa ser encarada por uma das partes, ainda que aparentemente, como uma tomada de posição em prol da outra.

Isso poderia restar evidenciado com a aceitação por parte do mediador de presentes ou dádivas de uma das partes ou ainda com a exposição de seus preconceitos a determinadas características pessoais de uma das partes. Tais acontecimentos fatalmente acarretariam a perda de confiança das partes no mediador, o que resultaria na frustração do processo de mediação. 
Outra questão que se encontra relacionada a esse princípio é aquela referente às hipóteses de suspeição e ao impedimento do mediador. O projeto de lei de mediação em curso no Brasil estabelece em seu artigo 21 que, aos mediadores e co-mediadores, aplicamse os impedimentos previstos nos artigos 134 e 135 do $\mathrm{CPC}^{7}$, estes, claro que, com as devidas e necessárias adaptações.

Art. 134. É defeso ao juiz exercer as suas funções no processo contencioso ou voluntário:

I - de que for parte;

II - em que interveio como mandatário da parte, oficiou como perito, funcionou como órgão do Ministério

Público, ou prestou depoimento como testemunha;

III - que conheceu em primeiro grau de jurisdição, tendo-lhe proferido sentença ou decisão;

IV - quando nele estiver postulando, como advogado da parte, o seu cônjuge ou qualquer parente seu, consangüíneo ou afim, em linha reta; ou na linha colateral até o segundo grau;

$\mathrm{V}$ - quando cônjuge, parente, consangüíneo ou afim, de alguma das partes, em linha reta ou, na colateral, até o terceiro grau;

VI - quando for órgão de direção ou de administração de pessoa jurídica, parte na causa.

Parágrafo único. No caso do no IV, o impedimento só se verifica quando o advogado já estava exercendo o patrocínio da causa; é, porém, vedado ao advogado pleitear no processo, a fim de criar o impedimento do juiz.

Art. 135. Reputa-se fundada a suspeição de parcialidade do juiz, quando:

I - amigo íntimo ou inimigo capital de qualquer das partes;

Assim é, por exemplo, que o mediador quando for cônjuge, parente, consangüíneo ou afim de algumas das partes, em linha reta ou, na colateral, até o terceiro grau, se encontrará impedido de exercer sua função naquele caso (hipótese do inciso V do artigo 134 do CPC).

Interessante e intrincada questão que daí resulta, todavia, é quando as partes são devidamente cientificadas a respeito de uma dessas hipóteses e, ainda assim, por força do princípio da voluntariedade das partes, preferem manter o mediador sob impedimento ou suspeição na direção do processo.

Nessa seara, é oportuno destacar que a American Arbitration Association, American Bar Association e Association For Conflict Resolution, por meio de seu "Model Standards of Conduct Mediators", na letra (c) de seu item "C", permite que as partes, após a revelação do mediador acerca de um possível conflito de interesses que possa colocar em xeque a sua atuação em determinada causa, possam concordar em mantê-lo, se assim o desejarem, hipótese em que ele (o mediador) poderá prosseguir no exercício de sua função ${ }^{8}$.

Contudo, assim não nos parece possível. Isso porque, quer seja nas hipóteses de impedimento, quer seja nas hipóteses de suspeição, acredita-se que tais institutos por se referirem a hipóteses, que carreiam em seu substrato valores de ordem pública, não podem 
vir a ser afastados pela mera vontade das partes, eis que, como se sabe, a observância da ordem pública é um limite à autonomia da vontade das partes.

Além disso, dificilmente um processo de mediação poderia se desenvolver regularmente e de maneira operosa, à luz de uma das hipóteses descritas nos artigos $134 \mathrm{e}$ 135 do CPC, sem comprometer, por outro lado, a necessária observância de algum dos princípios da mediação.

II - alguma das partes for credora ou devedora do juiz, de seu cônjuge ou de parentes destes, em linha reta ou na colateral até o terceiro grau;

III - herdeiro presuntivo, donatário ou empregador de alguma das partes;

IV - receber dádivas antes ou depois de iniciado o processo; aconselhar alguma das partes acerca do objeto da causa, ou subministrar meios para atender às despesas do litígio;

$\mathrm{V}$ - interessado no julgamento da causa em favor de uma das partes.

Parágrafo único. Poderá ainda o juiz declarar-se suspeito por motivo íntimo.

Por outro lado, esse entendimento se adequa mais perfeitamente a idéia de um processo justo, idéia esta plenamente compatível com esse mecanismo complementar de solução de disputas ${ }^{9}$.

Por outro lado, e ainda como decorrência do princípio da imparcialidade do mediador, vale a pena também destacar que o mediador, no exercício de sua função deve atuar de maneira independente - conforme, aliás, ressalta expressamente o artigo 14 do já citado projeto de lei de mediação ${ }^{3}$ - eis que não se concebe imparcialidade em quem não pode ser independente ${ }^{456}$.

\footnotetext{
${ }^{3}$ Para tanto, vide os artigos $1^{\circ}$ e $4^{\circ}, \mathrm{V}$ da Lei de Mediação Familiar de Castilla y León e artigo $1^{\circ}$ da Lei de Mediação Familiar de Valenciana, respectivamente:

Artículo. $1^{\circ}$. Objeto. Es objeto de la presente Ley regular la mediación familiar que se desarrolle en el ámbito de la Comunidad de Castilla y León. Se entiende, en este sentido, por mediación familiar la intervención profesional realizada en los conflictos familiares señalados en esta Ley, por una persona mediadora cualificada, neutral e imparcial, con el fin de crear entre las partes en conflicto un marco de comunicación que les facilite gestionar sus problemas de forma no contenciosa. Artículo 4 Principios informadores 5. Competencia profesional, ética, imparcialidad y neutralidad de la persona mediadora. Artículo. 1. De la mediación familiar. 1. La mediación familiar es un procedimiento voluntario que persigue la solución extrajudicial de los conflictos surgidos en su seno, en el cual uno o más profesionales cualificados, imparciales, y sin capacidad para tomar decisiones por las partes asiste a los miembros de una familia en conflicto con la finalidad de posibilitar vías de diálogo y la búsqueda en común del acuerdo. “(...) Mediation is a process in which an impartial third party facilitates communication and negotiation and promotes voluntary decision making by the parties to the dispute (...)"

5 La mediación es un procedimiento no formal, voluntario y bajo condiciones de confidencial, conducido por un tercero imparcial y aceptado por las partes de una disputa, que facilita el diálogo entre las mismas que haga posible un acuerdo convenido por aquéllas. BIANCHI, Roberto. Mediación prejudicial y conciliacion. Buenos Aires: Zavalía, 1996, p. 65. 6 Negociação. ADRS. Mediação. Conciliação e Arbitragem. Rio de Janeiro: Lumen Iuris, 2004, p.39
} 
Outra questão comumente ligada ao princípio da imparcialidade consiste em saber se ofende ou não o seu comando normativo uma intervenção mais ativa do mediador, a fim de eliminar possíveis desequilíbrios que afetem a capacidade negociadora das partes.

Sem desconhecer os problemas que podem advir dessa posição, principalmente se utilizada de forma abusiva e não operosa por parte do mediador, o certo é que se entende que o mediador não só pode, como tem o dever, de intervir de maneira cautelosa e adequada isto é, sem ofender os demais princípios e vulnerar os outros deveres, aos quais se encontra adstrito - para o fim de reestabelecer o equilíbrio entre as partes no processo de negociação.

Essa postura se utilizada de maneira adequada, mediante o uso de técnicas apropriadas, como a escuta ativa, a reformulação, a conotação positiva ${ }^{7}$, dentre outras, só vem a contribuir para o fortalecimento da confiança das partes, no manejo desse mecanismo de solução de disputas ${ }^{89}$.

Art. 14. No desempenho de suas funções, o mediador deverá proceder com imparcialidade, independência, aptidão, diligência e confidencialidade, salvo, no último caso, por expressa convenção das partes.

${ }^{4}$ Não há como imaginar a boa mediação sem independência, até porque a imparcialidade do mediador depende dessa independência, e cabe às partes escolherem ou aceitarem mediadores. SALES, Lilia Maria de Moraes. SALES, Lilia Maria de Morais. Justiça e Mediação de conflitos. Belo Horizonte: Del Rey, 2003, p.

\footnotetext{
${ }^{6}$ Por independência, compreende-se que ela expressa a necessidade da atuação do mediador vir a dar-se de forma livre de qualquer influência das partes ou de terceiros. Assim, não é permitida a existência de qualquer relação ou fator que submeta o mediador aos interesses de uma das partes; caso contrário, o processo de mediação deve ser imediatamente interrompido. Pinho. DALLA, Humberto Dalla Bernardina. (Org.). Teoria Geral da Mediação à luz do Projeto de Lei e do Direito Comparado. Rio de Janeiro; Lumen Iuris, 2008, p. 82

${ }^{7}$ Para maiores infomações sobre esse tema, vide o nosso trabalho ainda não publicado: não publicado. LOPES, Vitor Carvalho. "A Mediação como importante instrumento de efetivação do princípio do acesso à justiça: limites e possibilidades no sistema jurídico brasileiro". 2008. 197f. Dissertação de Mestrado - Universidade do estado do rio de Janeiro (UERJ), Rio de Janeiro, 2008.

8 “(...) este é o grande desafio da mediação, e o maior obstáculo ao sucesso desse processo de resolução de disputa. Como, ética e tecnicamente, o mediador tem de ser neutro, a forma de impedir que uma parte, mais poderosa, determine a solução do conflito, conforme seus únicos interesses, em detrimento dos interesses da outra, deve ser atentamente trabalhada pelo mediador. Em linhas gerais, é absolutamente ético a intervenção do mediador, no sentido de encaminhar dados ou pessoas que assistam a parte em desvantagem, para reforçar e equilibrar o poder e propiciar a negociação de forma mais eqüitativa (...)" SERPA, Maria de Nazareth. Teoria e prática da mediação de conflitos. Rio de Janeiro: Lumen Iuris, 1999.
}

$9^{6 “(. . .) ~ P o d e-s e ~ d i z e r ~ q u e ~ o ~ p r o j e t o ~ d e ~ l e i ~ d e ~ m e d i a c ̧ a ̃ o ~ o r a ~ e m ~ a n a ́ l i s e ~ a t e n d e ~ s a t i s f a t o r i a m e n t e ~ a o s ~ i d e a i s ~ d e ~}$ busca por uma solução segura e efetiva, na medida em que através da incidência de diversos dispositivos de ordem pública, mais especificamente de ordem processual, almeja não descuidar dos ideais de segurança que um processo de negociação comum poderia oferecer para a resolução de disputas, ao mesmo tempo em que prima por uma solução adequada e efetiva para esses tipos de disputas. Com isso, esse diploma normativo vem a evitar, de maneira satisfatória, as contundentes críticas que prestigiada doutrina já teve a oportunidade de fazer aos denominados mecanismos complementares de solução de disputas, no que se refere ao déficit que 
Imparcialidade, portanto, não pode ser confundida como sinônimo de passividade. O mediador deve participar ativamente do processo de negociação, a fim de eliminar eventuais distorções que rompam com o necessário equilíbrio que deve existir entre as partes.

A respeito desse tema, interessante doutrina ${ }^{10}$ formulou $\mathrm{o}$ conceito da multiparcialidade, o qual, em poucas palavras, vem a significar que é mais interessante que o mediador tenha uma atitude que tome partido por todos - isto é, multiparcial - do que uma atitude que não partido por nenhuma delas.

Por fim, cumpre ainda notar que tamanha é a necessidade de observância desse princípio em um processo de mediação que o projeto de lei de mediação expressamente determina para a hipótese de sua violação por parte do mediador, a abertura de processo administrativo sancionador, cuja pena não é outra, senão a sua imediata exclusão do registro de mediadores ${ }^{\mathrm{i} 11}$.

\section{Neutralidade do Mediador}

\subsection{Conceituação e importância}

Uma vez expostos os contornos básicos do princípio da imparcialidade, cumpre agora examinar um dos temas mais movediços, quando se trata de mediação, que é o chamado princípio da neutralidade. Comumente costuma-se utilizar indistintamente os termos imparcialidade e neutralidade, como se sinônimos fossem. Ocorre que na realidade não o são.

Em artigo paradigmático sobre o tema, o professor JOSÉ CARLOS BARBBOSA MOREIRA $^{12}$ bem elucidou a questão, ao explicar em poucas palavras que a imparcialidade,

esses tipos de métodos possuem, quanto à preservação das garantias fundamentais positivadas na Carta Maior (...)" Para maiores informações, vide o nosso trabalho ainda não publicado. LOPES, Vitor Carvalho. "A Mediação como importante instrumento de efetivação do princípio do acesso à justiça: limites e possibilidades no sistema jurídico brasileiro". 2008. 197f. Dissertação de Mestrado - Universidade do estado do rio de Janeiro (UERJ), Rio de Janeiro, 2008. p. 186.

9 “(...) La imparcialidad es definida como la posición de la persona mediadora que permite ayudar a ambas sin tomar partido por ninguna de ellas, respetando los intereses de cada parte, aunque es de la opinión de que la persona mediadora no rompe su imparcialidad si durante el proceso intenta eliminar los desequilibrios de capacidad negociadora, apoyando unas veces a una y otras a otra (...)”. PELÁEZ. Antonio Sastre. Los Principios Informadores de la Mediación Familiar; su reflejo en la Ley de Castilla y León y en otras Legislaciones Autonómicas del Estado Español. In: MARTIN, Nuria Belloso (Coord.). Estudios sobre Mediación: La Ley de Mediación de Castilla y León. Burgos: Junta de Castilla y León. 2006, p. 145.

${ }^{10}$ Para tanto, vide GARCIA, Lucia Garcia. GARCÍA. Lucía García. Mediación amiliar. Prevención y

Alternativa al litigio en los conflictos familiares. Madrid: Dykinson, 2003, p. 140/141.

${ }^{11}$ Art. 25 - Será excluído do registro de mediadores aquele que:

III - violar os princípios de confidencialidade e imparcialidade. 
em termos de comportamento do juiz, se revela quando a sua atitude não enseja favorecimento de tratamento a nenhuma das partes, ao passo que a neutralidade, se revelaria, quando o juiz tivesse um comportamento indiferente ao resultado do processo.

Nesse trabalho, o citado mestre, após expor essas idéias, conclui, ao final que o juiz deve manter-se sempre imparcial, mas que essa imparcialidade jamais deveria ser compreendida a ponto de se legitimar a total abstenção judicial em relação ao processo, permitindo que resultados injustos sejam produzidos, em razão da aparente necessidade de se respeitar esse postulado.

Diz-se aparente porque, nessa hipótese, não se estaria diante da problemática em torno do respeito ou não da imparcialidade, mas sim de verdadeira postura de neutralidade do juiz em relação ao processo, o que, na visão, desse processualista de maneira alguma é permitido ao juiz possuir. Isso se explica, pois, no exercício da jurisdição, cabe precipuamente ao juiz averiguar e proferir a resolução para o caso concreto, conforme o sentido preconizado pela lei, não se podendo permitir nessa seara, que se alcance resultados em desconformidade com ela.

Assim, transplantando esses conceitos para a mediação, onde, ao contrário da jurisdição, são as próprias partes dissidentes as responsáveis pela tomada de uma decisão que ponha fim a seu litígio, é natural concluir que o mediador, ao contrário do juiz, deve, em princípio, ser neutro.

Isso porque, como dito acima, são as próprias partes em disputa que são as responsáveis pela obtenção de uma decisão nesse campo, sendo ilegítima qualquer solução que seja

\footnotetext{
12 “(...) Dizer que o juiz deve ser imparcial é dizer que ele deve conduzir o processo sem inclinar a balança, ao longo do intinerário, para qualquer das partes, concedendo a uma delas, por exemplo, oportunidades mais amplas de expor e sustentar suas razões e de apresentar as provas de que disponha. Tal dever está ínsito no de "assegurar às partes igualdade de tratamento", para reproduzir os dizeres do art 125, $\mathrm{n}^{\circ}$ I do Código de Processo Civil. Outra coisa é pretender que o juiz seja neutro, no sentido de indiferente ao êxito do pleito. Ao magistrado zeloso não pode deixar de interessar que o processo leve a desfecho justo; em outras palavras, que saia vitorioso aquele que tem melhor direito. Em semelhante perspectiva, não parece correto afirmar, sic et simpliciter, que para o juiz "tanto faz" que vença o autor ao que vença o réu. A firmação só se afigura verdadeira enquanto signifique que ao órgão judicial não é lícito preferir a vitória do autor ou a do réu, e menos que tudo atuar de modo a favorecê-la, por motivos relacionados com traços e circunstâncias pessoais de um ou de outro: porque o autor é X, simpático ou porque o réu é Y, antipático ou vice-versa (...)” MOREIRA, José Carlos Barbosa. Reflexões sobre a Imparcialidade do Juiz. In: Temas de Direto Processual Civil, $7^{a}$ Série. Editora Saraiva: 1994, p. 19/30.
} 
sugerida ou mesmo imposta pelo mediador, pro força do princípio da autocomposição das partes $^{13}$, outro postulado de nítida incidência nesse campo.

Desse modo, com a elevação do conceito de neutralidade ao nível de um princípio da mediação, percebe-se que o legislador quis evitar que o mediador imponha, oriente, ou formule sugestões quanto mérito da disputa, ou de alguma forma influa no resultado final da mediação, conferindo uma solução a ela, segundo a sua própria escala de valores, o que se daria em manifesto contradição a toda sistemática da mediação.

É, pois, dessa forma que se deve entender o princípio da neutralidade.

\subsection{Alcance prático}

A grande questão prática decorrente da incidência desse princípio reside em fixar a exata fronteira para o princípio da neutralidade, a fim de que, por um lado, reste nitidamente observado o seu conteúdo, sem que, por outro reste comprometido a sua necessária e imprescindível intervenção na disputa, quando for preciso.

Nesse contexto, é preciso destacar que tal princípio, ainda que compreendido nos termos acima enunciados, não pode ser levado a efeito, com extremo rigor. Em outros termos, a neutralidade aqui exposta jamais pode ser interpretada de maneira absoluta, eis que qualquer intervenção do mediador na disputa a ele submetida poderia ser interpretado, como uma forma de imposição de suas percepções pessoais, seus valores, concernentes ao mérito da disputa, o que, na prática, acabaria por inviabilizar qualquer intervenção de sua parte, o que, de modo algum, parece razoável admitir.

Nesse particular, é de bom alvitre salientar que mesmo para quem admite o princípio da neutralidade como um enunciado a guiar a postura do mediador, o faz com certas ressalvas ${ }^{14}$.

\footnotetext{
13 ، (...) Quando se alude ao princípio da autocomposição em termos de mediação objetiva-se demonstrar que toda a sistemática desse mecanismo de solução de disputas se dirige para o alcance de uma decisão que não vem imposta por terceiros a disputa, mas sim pelas próprias partes. Em outros termos: não há imposição de qualquer decisão proferida por um terceiro (no caso, o mediador) às partes que se encontram sujeitas ao processo de mediação. Ao contrário, portanto, da jurisdição ou mesmo da arbitragem em que a decisão é proferida por um terceiro, na mediação a decisão é alcançada, mediante um estruturado processo de negociação, capaz de propiciar o alcance de uma decisão concertada, consensuada, que contemple, na medida do possível, todos os interesses das partes em conflito, sejam eles meramente econômicos, emocionais, psicológicos e não meramente jurídicos (...)”LOPES, Vitor Carvalho. “A Mediação como importante instrumento de efetivação do princípio do acesso à justiça: limites e possibilidades no sistema jurídico brasileiro". 2008. 197f. Dissertação de Mestrado - Universidade do estado do rio de Janeiro (UERJ), Rio de Janeiro, 2008. p. 65/66.
} 
Isso porque se reconhece que a neutralidade como um fim em si mesmo, ou melhor, como um constante modo de atuar do mediador durante todo o processo de mediação é, no mínimo, uma idéia não realista.

Assim ocorre porque, nessa hipótese, se teria um mediador como um ser estático, sem valores, que, por apego irrestrito a esse princípio jamais interviria na disputa, revelando, com isso, certa indiferença em relação a ela.

Baseado nessa idéia, há autores ${ }^{15}$ que negam mesmo a existência de neutralidade do mediador, levando-os afirmar que, tal como os juízes, os mediadores só seriam imparciais. Nesse quadro, cabe ressaltar que a neutralidade compreendida sob esses termos é um mito inalcançável. Além disso, é uma idéia que praticamente inutiliza a figura do mediador, retirando dele toda a contribuição que ele é capaz de oferecer para o alcance de uma solução adequada para a disputa.

Nessa visão, percebe-se que a própria operosidade da mediação restaria vulnerada se esse princípio viesse a ser interpretado ao extremo.

Verifica-se, desse modo, que a grande pedra de toque do princípio da neutralidade reside em compatibilizar o seu real desiderato com a necessária e adequada intervenção que o mediador deve possuir na apreciação da disputa a ele submetida. Se tal compatibilização não for possível, a saída parece mesmo acompanhar aqueles que negam a aplicação desse princípio para o mediador. Ocorre que essa solução por demais simplista, muitas das vezes, arremete contra texto literal de lei.

Assim é que no âmbito do direito estrangeiro o princípio da neutralidade vem consagrado em praticamente todos os diplomas legislativos que versam sobre mediação.

\footnotetext{
${ }^{14}$ Para tanto, vide PELÁEZ, Antônio José Sastre. op. cit. p. 148.

${ }^{15}$ Preferimos hablar de imparcialidad y no de neutralidad por tres motivos. En primer lugar, la palabra "neutralidad" tiene una connotación de no compromiso con relación a los "beligerantes", e implica fundamentalmente un deber de no intervención en el conflicto. Por el contrario, el mediador debe justamente intervenir para tratar de facilitar el diálogo con miras a la resolución del conflicto. Asimismo está precisamente comprometido con las partes, y debe servir a ambas por igual. En segundo lugar, la palabra "neutralidad" puede aludir a una cierta "objetividad" con la que debería comprometerse el mediador. Esa no es, sin embargo, una presunción realista. Lo cierto es que no existe una "objetividad" en tal sentido, cuestión de la que se ocupa Kotliar en el capítulo 5, numero 34. En tercer lugar, el concepto de neutralidad puede implicar en algún sentido una cierta cuota de inacción o de "indiferencia", y no tenemos duda que el rol del mediador es por una parte de notoria actividad, así como de compromiso con su responsabilidad de fomentar las actitudes razonables, evitando que tanto los resultados del conflicto, como el arreglo alcanzado, no afecten a terceros no representados en el procedimiento, o al público en general. BIANCHI. Roberto. Op. cit., p. 173.
} 
Nesse contexto, é oportuno destacar que a Recomendação no 98 (1) do Conselho de Ministros da União Européia, que versa sobre a mediação familiar o elenca como um de seus princípios norteadores. Por sua vez, seguindo a orientação dessa Recomendação, a Lei de mediação da Comunidade Autônoma de Castilla y León contempla expressamente esse postulado como seu princípio orientador ${ }^{22}$. A Lei de mediação da Comunidade Autônoma de Madrid também segue nessa mesma linha, ao estatuir que tanto a imparcialidade, como a neutralidade são princípios informadores desse mecanismo de solução de disputas ${ }^{23}$.

A lei de mediação argentina não trata expressamente da neutralidade. Somente alude em seu artigo 11 que o mediador deverá ter o cuidado de não favorecer, através de sua conduta, a qualquer das partes. Já o projeto de lei de mediação em curso no Brasil parece também adotar o princípio da neutralidade em sua sistemática ${ }^{24}$.

A problemática em torno desse tema resta sensível, quando se constata que qualquer intervenção humana pode ensejar ainda que de forma suave a percepção do mediador acerca de determinado assunto, seja esta identificável por meio da linguagem utilizada por ele, de sua interpretação a respeito das informações ali trocadas, seja mesmo mediante a manifestação de seus valores e/ou suas percepções a respeito da disputa.

Sob essa ótica, qualquer intervenção do mediador seja em que sentido for, poderá ser considerada como uma violação a esse princípio.

Para exemplificar, imagine-se uma intervenção do mediador no sentido de reequilibrar as forças no processo de negociação entre as partes, mediante a formulação de questões a uma delas, de maneira a permitir-lhe a considerar um aspecto até então ignorado por ela, mas de absoluta importância para uma correta avaliação da disputa. Será que uma intervenção nesse moldes poderá ser considerada atentatória a esse princípio? A doutrina certamente acredita que não, posição essa com a qual inteiramente se concorda.

Neutralidade, portanto, em termos de mediação, definitivamente não quer supor ausência de intervenção do mediador.

Mas, se assim é, qual seria fronteira em que determinada intervenção seria atentatória à idéia de neutralidade do mediador, ou mesmo, a contrario sensu, em que hipóteses elas seriam admissíveis?

A reposta a essa questão não é de simples formulação. Todavia, realizando uma interpretação teleológica a esse princípio, reputa-se que a sua finalidade é impedir o mediador de expor às suas opiniões pessoais quanto ao mérito em si da disputa, a fim de 
evitar que as partes ou mesmo uma delas se apeguem a uma medida concreta, formulada segundo a escala axiológica do mediador. Isso porque, conforme acima visto, ao contrário da jurisdição, são as partes as únicas e exclusivas responsáveis pela solução de sua disputa. Se assim é, a neutralidade do mediador estaria a princípio observada, quando na fase de elaboração de acordo, ele se restringisse a não realizar qualquer sugestão concreta quanto ao mérito do conflito, deixando, com isso, que as partes assim livremente o decidam. O limite dessa livre atuação das partes estaria também na lei, eis que não se admite acordos que versem sobre objetos ilícitos, ou cujos agentes sejam incapazes, ou ainda quando as suas respectivas formas estejam em dissonância com o que está prescrito na lei.

Caso uma dessas hipóteses ocorra, o mediador deve alertar as partes sobre tal fato, mas jamais pode propor uma medida específica em sua substituição. Tal dever resta manifesto, quando se contata que o mediador deve zelar por um processo realmente efetivo. Afinal, a ele não interessa que um processo de mediação chegue a um resultado que ele sabe de antemão não poder possuir efeitos concretos. Em um sistema de mediação, no qual estipula que o acordo nele obtido constituirá título executivo extrajudicial, tal como o nosso ${ }^{16}$, essa constatação resta ainda mais evidente.

\footnotetext{
${ }^{16}$ Para tanto, vide o artigo $7^{\circ}$ do projeto de lei que institucionaliza e disciplina a mediação paraprocessual civil. 22 Artículo 4. Principios informadores 5. Competencia profesional, ética, imparcialidad y neutralidad de la persona mediadora. 23 Artículo 4. Principios de la mediación familiar Las actuaciones de mediación que se lleven a cabo en desarrollo de la presente Ley se fundamentarán en las siguientes normas:

c) Imparcialidad y neutralidad del mediador actuante, que no podrá adoptar decisiones alineándose de forma interesada con parte alguna, influirlas o dirigirlas hacia la consecución de soluciones conforme a su criterio personal o imponer soluciones.

${ }^{24}$ Para tanto, veja-se o teor do art. 24 do referido diploma:

Art. 24. Considera-se conduta inadequada do mediador ou do co-mediador a sugestão ou recomendação acerca do mérito ou quanto aos termos da resolução do conflito, assessoramento, inclusive legal, ou aconselhamento, bem como qualquer forma explícita ou implícita de coerção para a obtenção de acordo.

${ }^{26}$ Princípio esse, aliás, que é uma constante em todos os demais países que a adotam. Nesse sentido, note-se também o item II do diploma aprovado pela American Arbitration Association, American Bar Association e Association for Conflict Resolution denominado "Model Standards of Conduct for Mediators" que assim estabelece:

Standard II Impartiality

A. A mediator shall decline a mediation if the mediator cannot conduct it in an impartial manner. Impartiality means freedom from favoritism, bias or prejudice.

B. A mediator shall conduct a mediation in an impartial manner and avoid conduct that gives the appearance of partiality

1. A mediator should not act with partiality or prejudice based on any participant's personal characteristics, background, values, and beliefs, or perfomance at an mediation, or any other reason.

2. A mediator should neither give nor accept a gift, favor, loan or other item of value that raises a question as to the mediator's actual or perceived impartiality.
} 
Por fim, no que tange às fases anteriores à elaboração do acordo, acredita-se que as intervenções do mediador serão legítimas, desde que elas tenham como fundamento de sua ocorrência o estabelecimento de um ambiente mais propício e adequado às partes a negociarem, pautado pela observância integral da igualdade e boa fé.

O que esse postulado assim almeja, é deixar sem sombra de dúvidas separado o que o mediador reputa como devido para a solução da disputa a ele submetida e o que as partes realmente desejam, coibindo, com isso, que o mediador emita as suas opiniões pessoais a respeito da solução da disputa, o que desvirtuaria a própria ratio essendi da mediação, conforme acima exposto.

\section{Síntese Conclusiva}

Comumente costuma-se utilizar os vocábulos imparcialidade e neutralidade, a fim de designarem o mesmo fenômeno, como se sinônimos fossem.

Ocorre que, como visto, eles não o são. Tal assertiva jamais se consubstanciou verdadeira no âmbito do processo jurisdicional, que dirá no âmbito do processo de mediação.

Nesse cenário, cumpre ressaltar que tais postulados ganham especial relevo no âmbito desse mecanismo complementar de solução de disputas, consubstanciando-se em verdadeiros princípios a nortearem a atuação do mediador em tal contexto.

Nesse sentido, deve-se entender a imparcialidade como a proibição de qualquer conduta por parte do mediador que importe em qualquer favorecimento de tratamento a uma das partes.

A neutralidade, por sua vez, deve ser entendida como a proibição imposta ao mediador consistente no ato de orientar ou mesmo formular sugestões quanto mérito da disputa, ou que de alguma influa no resultado final da mediação, conferindo uma solução a ela, segundo a sua própria escala de valores.

3. A mediator may accept or give de minimis gifts or incidental item or services that are provided to facilitate a mediation or respect cultural norms so long as such practices do not raise questions as to a mediator's actual or perceived impartiality. 
Nesse desiderato, entretanto, restou também evidenciado que não se deve confundir a neutralidade com uma suposta ausência de valores por parte do mediador, o que seria de todo impossível.

Tampouco se deve a neutralidade com uma suposta passividade do mediador, que deverá agir, diante das hipóteses, fundamentos e visando atingir aos objetivos acima elencados.

Por outro lado, a partir do quadro acima exposto, fica fácil perceber que, dado às múltiplas situações que decorrem da incidência desses princípios, tanto a imparcialidade, como a neutralidade do mediador se constituem em princípios fundamentais para uma adequada compreensão da mediação ${ }^{26}$.

Desse modo, a correta compreensão e análise do enquadramento dos contornos básicos desses princípios, bem como a análise adequada de suas decorrências práticas somente contribuirão para uma maior operosidade desse novo mecanismo de solução de disputas.

Somente a partir daí, já dá para se ter uma idéia como o sucesso e a credibilidade da mediação se encontram visceralmente ligados à observância desses princípios.

5. Bibliografia

ALVAREZ, Gladys Stella. La mediación y el acesso a justicia. Buenos Aires: RubinzalCulzoni, 2004.

ARÉCHAGA, Patrícia; Brandoni, Florência; Risolia, Matilde. La trama del papel. Sobre el processo de mediación, los conflictos y la mediación penal. Buenos Aires: Galerna, 2005.

AZEVEDO, André Gomma de. (Org.) Estudos em Arbitragem, mediação e Negociação Vol. 1. André Gomma de Azevedo. Brasília: Grupos de pesquisa, 2004.

BACELLAR. Roberto Portugal. Juizados Especiais. A nova mediação paraprocessual. São Paulo: Revista dos Tribunais, 2003. 
BIANCHI, Roberto. Mediación prejudicial y conciliacion. Buenos Aires: Zavalía, 1996

CAIVANO, Roque J.; GOBBI, Marcelo; PADILLA, Roberto E. Negociación y Mediación: Instrumentos apropiados para la abogacía moderna. 2. edición actualizada y ampliada. Buenos Aires: Ad-Hoc, 2006.

CALMON, Petrônio. Fundamentos da Mediação e da Conciliação, Rio de Janeiro: Forense, 2007.

CAPPELlETTI, Mauro. Os Métodos Alternativos de Solução de Conflitos no Quadro do Movimento Universal de Acesso à Justiça. [s/ indicação de tradutor], Revista Forense. Rio de Janeiro, v. 326, p. 121-130, abr./jun. 1994.

Acesso dos consumidores à justiça. [s/ indicação de tradutor]. Revista Forense, Rio de Janeiro, v. 310, p. 53-63, abr./jun. 1990.

. Acesso à justiça e a função do jurista em nossa época. Revista de Processo. São Paulo: Revista dos Tribunais, ano 16, n. 61, p. 144-160, jan./mar. 1991

Juízes Irresponsáveis? Tradução de Carlos Alberto Álvaro de Oliveira. Porto Alegre: Fabris, 1989.

Mauro; GARTH, Bryant. Acesso à Justiça. Tradução e revisão de Ellen Gracie Northfleet. Porto Alegre: Sérgio Antônio Fabris Editor, 1998

CAMPILONGO, Celso Fernandes. Política, sistema jurídico e decisão judicial. São Paulo: Max Limonad, 2002.

DINAMARCO, Cândido Rangel da Silva. A Instrumentalidade do processo. São Paulo: Malheiros, 2003. 
GARCÍA. Lucía García. Mediación Familiar. Prevención y Alternativa al litigio en los conflictos familiares. Madrid: Dykinson, 2003

GRINOVER, Ada Pellegrini; CINTRA, Antônio Carlos de Araújo; DINAMARCO, Cândido Rangel. Teoria geral do processo. São Paulo: Malheiros, 2001.

HORTA, Fernando. Mediação e Conciliação. Belo Horizonte: Mandamentos, 2002.

LIMA FILHO, Francisco das Chagas. Acesso à justiça e os mecanismos extrajudiciais de solução de conflitos. Porto Alegre: Fabris, 2003.

LOPES, Vitor Carvalho. "A Mediação como importante instrumento de efetivação do princípio do acesso à justiça: limites e possibilidades no sistema jurídico brasileiro”. 2008. 197f. Dissertação de Mestrado - Universidade do Estado do Rio de Janeiro (UERJ), Rio de Janeiro, 2008.

MARÍN. María Josefa Ruiz. Mediación y protección de menores en Derecho de Família. Coordenação: María Josefa Marín. Madrid: Cuadernos de de Derecho Judicial, v. 5, Consejo General del Poder Judicial.

MARTIN, Nuria Belloso (Coord.). Estudios sobre mediación: la ley de mediación familiar de Castilla y León. Nuria Bellosos Martin. Junta de Castilla y Léon: Consejería de Familia e Igualdad de Oportunidad, 2006.

MOREIRA, José Carlos Barbosa. O processo, as partes e a sociedade. Revista Dialética de Direito Processual. São Paulo, v. 5, p. 32-40, ago. 2003.

. Temas de Direito Processual. 6ª Série. Rio de Janeiro: Saraiva, 1997.

. Temas de Direito Processual. $7^{\text {a }}$ Série. Rio de Janeiro: Saraiva, 2001.

. Temas de Direito Processual. $8^{\text {a }}$ Série. Rio de Janeiro: Saraiva, 2004. 
MUÑOZ, Soleto Helena; PARGA, Milagros Otero (Coords.). Mediación y Solución de conflictos. Habilidades para uma necessidad emergente. Madrid: Tecnos, 2007.

NERY JÚNIOR, Nelson. Princípios do processo civil na Constituição Federal. São Paulo. Revista dos Tribunais, 2002.

PARKINSON. Lisa. Mediación Familiar. Teoría y práctica: principio y estratégias operativas. Barcelona: Gedisa, 2005.

PINHO, Humberto Dalla Bernardina de. Mecanismos alternativos de solução de conflitos: algumas considerações introdutórias. Revista Dialética de Direito Processual Civil. São Paulo. v. 17, p. 9-14, ago. 2004.

. DALLA, Humberto Dalla Bernardina. (Org.). Teoria Geral da Mediação à luz do Projeto de Lei e do Direito Comparado. Rio de Janeiro; Lumen Iuris, 2008.

Mediação. A redescoberta de um velho aliado na solução de conflitos. In: Acesso à Justiça; efetividade do processo. PRADO, Geraldo (Org). Rio de Janeiro; Ed. Lumen Iuris, 2005.

SALES, Lilia Maria de Morais. Justiça e Mediação de conflitos. Belo Horizonte: Del Rey, 2003.

SAMPER, Trinidad Bernal. La Mediación. Una solución de los conflictos de ruptura de pareja. $3^{\mathrm{a}}$ ed. Madrid: Editorial Colex, 2006.

SERPA, Maria de Nazareth. Teoria e prática da mediação de conflitos. Rio de Janeiro: Lumen Iuris, 1999.

SILVA, João Roberto. A mediação e o processo de mediação. São Paulo: Paulistanajur, 2004. 
Quaestio Iuris

SUARES. Marines. Mediación. Conducción de disputas, comunicación y técnicas. Paidós, Buenos Aires, 2004. 